E S SAY

\title{
Being intimate \\ on affective methodologies \\ and laboratory work
}

\section{By TARa Mehrabi}

\section{Abstract}

Situated within feminist technoscience studies and affect theory, this article explores the methodological specificities of working with Drosophila Melanogaster, commonly known as fruit flies. Based on a year of participatory observation in a fly lab, the article challenges the modernist imaginaries of laboratory work as disembodied, detached and objective. It suggests that laboratory work is instead an interactive, embodied and affective process that takes place in proximity between human and non-human, subject and object. The article therefore contributes to earlier feminist science studies arguing that doing science is an interactive, procedural, socio-cultural phenomenon. However, while most such previous works focus on issues such as connections, companionship, love and empathy, this article asks what methodological contributions can come from experiencing the intensity of more than human encounters that inspire undesirable feelings such as disgust.

\section{KEYWORDS}

Intimacy, fruit fly, feminist technoscience, affect, laboratory

Tara Mehrabi holds a Ph.D in Gender Studies and is a postdoc at the University of Turku. Her research interests are feminist technoscience studies; gender, health and medicine; feminist posthumanities; new materialism and feminist ethnography. 


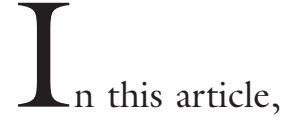

I use ethnographic material collected from a year of participatory observation in an Alzheimer's laboratory in Sweden in which scientists work with Drosophila Melanogaster, commonly known as fruit flies. Situated within feminist technoscience studies and affect theory, I argue that doing science in the lab and working with flies is an intimate, embodied, intra-active and affective process through which the object and subject of research co-produce one another (cf. Barad 2007; Mayers 2015). I use the term becoming fly-sensitized in order to highlight the material-discursive transformative processes of knowledge production in the lab. I discuss how I became a Drosophilist through everyday practices of doing Alzheimers disease (AD) science, as I had to learn to see, move and feel differently with the flies. Last but not least, I explore my subjective relationship with the flies and the sensation of disgust I constantly felt while working with them. I discuss disgust not as an emotion, but as an affective methodological tool which not only captures the intra-active and material-discursive modes of doing science, but which also enables me to ask different research questions, such as whose lives matters within the contemporary science economy. I also ask what kinds of empirical material one can collect by thinking through the concept of intimacy as affective encounters that are not inspired by the warm feelings of love and companionship that fluffy animals such as dogs trigger (Haraway 2008), but instead are saturated with the repellent intensity of disgust and discomfort of being intimate with the abject, here fruit flies. Finally I ask whether, in thinking through multi-species intimacy, one can rethink ethics as a relational process of becoming with that extends beyond the comfort zone of "nearby geographies" (Bull 2014).

\section{INTIMACY AND}

\section{AFFECTIVE METHODOLOGIES}

In the humanities and social sciences, the notion of intimacy has often been discussed in relation to partnership, family life, care and reproduction (cf. Jamieson 2011; Jankowiak and Paladino 2008). My own contribution approaches the concept of intimacy through material feminism, in which the unit of analysis is the material-discursive, human-nonhuman, social, technological and biological relations that together are performative of bodies and the worlds they inhabit (e.g. Barad 2007; Alaimo \& Hekman 2008). In this theoretical approach, entities are always already a "contact zone", to use a term coined by the feminist technoscience scholar Stacy Alaimo, materialized through situated relations. This approach embodies a critique of "human exceptionalism" (Haraway 2008) that takes the human subject (often the white, heterosexual, European man) to be at the center of the world and separated from the rest of it, including nature and the non-human other. The approach promotes a more inclusive understanding not only of humans, but also of the "subjects of a life" (Birke et al. 2004, 174), thus acknowledging the entanglement of human bodies with other life forms, as well as human abilities and consciousness as always already multispecies (see Nayar 2014). It is this multispecies relationality that I find important in understanding intimacy in the laboratory. In other words, intimacy as yet another fuzzy category is traditionally bound to the subject, understood as a human attribute and embedded in binaries such as public-private, nature-culture, self-other (mentioned in Jamieson 2011). However, as feminist scholars such as gender studies scholars Wibke Straube (forthcoming) and Helga Sadowski (2016) have argued, among others, intimacy transgresses the classical binaries of nature-culture, body- 
technology, and human-nonhuman. For instance, Straube's work on intimacy draws on the relationality between the "deviant" human body and polluted nature that, instead of reinforcing the hierarchical prioritization of the human body, suggests a new understanding of non-hierarchical relationality with nature and ecological others.

My interest in the concept of multispecies intimacy is also a methodological one. The gender studies and animal studies scholar Kathryn Gillespie (2017) uses the term as a methodological tool for analyzing more than just human performative practices of doing science. According to her, intimacy is entangled with empathy, being "a type of caring perception focused on attending to another's experience of wellbeing", a blend of emotion and cognition in which we enter into relations with others, animals, the environment and the world. We are therefore called upon to be responsible and to attend to other's diverse modes of vulnerability and situated needs. In laboratory work, therefore, intimacy is a matter of paying attention to lived experiences through what Gillespie calls a "slow-research" process that takes particularities and details as its point of departure. This is a time-consuming process: being attentive to and accountable for such local particularities and intimacies necessitates, as the environmental humanities scholar Timothy Morton argues:

"thinking and practicing weakness rather than mastery, fragmentariness rather than holism, and deconstructive tentativeness rather than aggressive assertion” (Morton 2010, 278).

Although I take the notion of multispecies intimacy from Gillespie (2017), my understanding of the concept is slightly different. First, intimacy is not innocent but potentially violent (Pain 2014), particularly within the context of laboratory work. In fact, as the feminist technoscience scholar Tora Holmberg (2011) argues, laboratory work is embedded within an economy of "mortal love" in which intimacy simultaneously coexists with distance. In other words, scientists simultaneously care for the animal, yet also use it in experiments and eventually kill the animal which they are usually able to do because they distance themselves from it, although it is the object of their care and love. Scientists strive to practice killing well and killing with care. Care, empathy and intimacy here constitute complex relations that goes beyond just empathy with others and attending to their needs.

Secondly, I relate the concept of intimacy to affect theories rather than emotion. According to aesthetics and communication scholars Britta Knudsen and Carsten Stage:

"affects travel between (human and non-human) bodies and are experienced subjectively", yet "they are often perceived as surprising or somehow beyond the will and conscious intentionality of the affected body" (Knudsen and Stage 2015,5 ).

In my understanding, therefore, intimacy is an affective material-discursive process that, according to Sadowski (2016), shapes bodies and the worlds they inhabit in relation to other bodies that are not necessarily human. Through affective intimacy, bodies perform one another, animate each other simultaneously. Feminist technoscience scholar Natasha Myers (2015) calls this "intra-animacy". Following Sadowski, therefore, affective intimacy is an embodied performative relationality that "is not necessarily related to feelings and emotion, although they might emerge in the mix of affects, which is affection" $(2016,51)$.

\section{ON BECOMING FLY-SENSATIZED}

Field note April, 2012: A visit to the laboratory. The same sensation of disgust that always makes me feel nauseous hits me again, even before I enter the lab. The flies. The 
flies are haunting me. They are getting into me. I put on my white lab coat. I am sitting behind the microscope, holding my brush. Turning the tube and bouncing it on the plate; the plate releases nitrous oxide. The flies fall asleep on the plate. I push it under the microscope. The legs are frozen straight upward as if they are dead. The legs are pointing at me. The two front legs look like a sharp arrow, following the rest of the body. Looking at it through the lens of the microscope, the arrow is piercing through me. I can't breathe. My pulse rises up. The arrow changes as the fly moves, the fly is alive. I am shocked. Pushing the first tube away, I take the next one, trying to forget about the fly inside me. Try to forget that it is moving, crawling and growing. That it is taking over. Repeat to myself like a mantra: curly wings, red eyes, hairs on the shoulder. Trying to imagine that I am picking berries and separating the black berries from the white ones. The black ones are male, the white ones are female. ${ }^{1}$ I try to focus on the colours only and the hair as if they are disembodied, as if there is no fly. As if my body closes up in this act of disembodiment. I rub my hands against the white coat. My skin is not the barrier, but the white coat is. What is it about the white coat? It is a sense of security and protection, I guess. It resonates with cleanliness and control. It is where my body ends and the flies' bodies begin. It is the distinct line. It is an extra skin. It detaches me, distances me and protects me from touching and being touched, from closeness and connection. As if nothing can pierce in and nothing can get out. Closed and clean. The border between the inside and outside. The non-negotiable border between 'I' and the flies: steady, fixed with the long history of modernity and human exceptionalism. The flies move inside me again. The white coat is a fraud! I ask, who are you who are so strangely me?

One of the first things I learned in the lab was to work with the microscope to tell the sex of the flies. The first time I looked at one, I was disoriented. I had to sedate the transgenic fruit flies and put them on a plate under the lens. I used sedation to make them lie still so that they would not move away. However, sedation was risky for the flies. It would have killed them had I left them sedated for a long time. Looking through the microscope itself, I was simultaneously becoming intimate with the flies while distancing myself from them, as I objectified them in terms of their disembodied body parts such as hair and eyes - an act of distancing that allowed me to kill them in large numbers. This meant embodying the intensity of mortal love, as I both cared for the flies and killed them with care. Embodying mortal love enacted me as the AD technician in the lab as much as it enacted the transgenic fruit flies under my microscope as objects of exploration.

I had to learn how to synchronize my hand, holding and moving the brush and pushing and pulling the flies with it at the right angle and with the right amount of pressure so as to avoid squashing them or knocking them off the plate. ${ }^{2}$ I had to learn to coordinate my hand movements with my vision while looking through the microscope, which was far from familiar. And I had to learn to see and recognize the 'right'3 transgenic fruit flies quickly. As the anthropologist of science Natasha Myers argues, laboratory work requires technicians to "engage their bodies actively in their work" $(2015,1)$. She calls this the "kinesthetic" of practicing science, that is, "the visceral sensibilities, movements, and muscular knowledge that modelers bring to their body experiments". In a similar vein, Tora Holmberg argues that:

“experimentalists-in-the-making must (...) become habituated to the laboratory animals. To get the right grip, [they] must get to know the animal" (Holmberg 2008, 322).

So, I had to get habituated to the practices 
of working with the flies and its technologies, as well as to my own extended body, to my new sense of vision and to my extended hand with the brush. But I also had to care for the flies, not only in terms of mindfulness but in material ways, as I touched them, fed them, changed their tubes, looked at them and poked them with the brush under the microscope: I had to become fly-sensitized. Becoming fly-sensitized is a matter of embodied intimacy and intra-animacy, as I had to habituate myself to the transgenic fruit flies, their bodies, their movements and their bodily vulnerabilities and needs. This, according to Gillespie (2017), is the dynamic aspect of multispecies intimacy. Thus I was as much enacted as a drosophilist as the dosophila was enacted as a test object.

Becoming fly-sensitized brings to the fore an alternative mode of scientific practice to modernist ways of doing science. In other words, claiming the position of becoming fly-sensitized helps me move away from the ideal of progressive scientific discoveries that is accompanied by narratives and practices of domination, of the conquest and exploitation of nature as passive and inferior. Instead, to go back to Timothy Morton again $(2010,278)$, it helps to think with and practice weakness "rather than mastery, fragmentariness rather than holism, and deconstructive tentativeness rather than aggressive assertion".

To work through the embodied intimacy and situatedness of scientific practices in a fly lab underlines the importance of feminist modes of doing science and care. It also highlights the existing power relations that are constitutive parts of everyday practices of doing life science and the facts produced in the laboratory. This supports the argument that care is not innocent, care and caring for transgenic fruit flies being entangled with killing (see also Holmberg 2011) and embedded in a relationship of use (Haraway 2008).

\section{DISGUST AND ETHICS}

My becoming fly-sensitized was also a matter of my personal relationship with the flies. I have always hated flies - or at least been disgusted by them. Imagine my face upon entering the lab and realizing that I had to look at dozens of fruit flies every day, not from the safety of a distant, closed vial, but closely magnified under the lens of the microscope. The first time I had such an encounter, I managed to control myself for over twenty minutes before the dizziness and nausea overwhelmed me, and I had to let go. I had to go to the coffee room, find an empty couch and lie down for some minutes until my vision became clear again. That was what the intensity of working with the flies meant to me. Imagine also my ethical dilemma over the prospect of killing them, which gave me guilty pleasure. The funny thing was that I did not experience such a strong dilemma over killing them in the kitchen in our collective. On the contrary, I would hysterically chase them around and smash them against the wall. But it felt different in the lab. The very fact that I was wearing the white coat and had control over their lives put me in the awkward position of experiencing an ethical dilemma, which is what inspired me to write my dissertation about human-animal relations and the ethics of killability in laboratory practices.

Nonetheless I used disgust as a tool with which to explore ethics in the lab. I realized that disgust is ethically important, not only because it made me sick or because it exposed an ethical dilemma in the lab over whether to kill a living organism for scientific purposes or not. Disgust was ethically important to me because it communicated my anxieties to me about science, laboratory, death, disease, waste and flies. As Sara Ahmed (2014) argues, feelings such as disgust are closely linked to social abjection; they are cultural, historical stories that are associated with particular bodies. Moreover, such feelings are not something abstract that happens inside a subject, but affective 
performative bodily realities that happen between bodies and through close intimate encounters. These feelings do things, materializing realities in different ways. Inspired by Ahmed, among others, Jacob Bull (2014), writing about ticks, discusses the possibilities of an ethical response to negatively loaded encounters that are accompanied by feelings such as disgust, fear and repulsion rather than love and compassion. In fact, he identifies a limit within ethical writing about human and animal encounters, in which only animals that are close to humans have been the object of ethical concern. As Bull (2014) argues, accounts of multispecies ethics or the ethics of relationality are often limited to those animals with which humans have close relations, such as domestic animals, "companion species" (Haraway 2008), animals on which we rely for food (Twine 2010) and at certain points laboratory animals with which we recognize kinship as fellow mammals, such as apes and mice (Haraway 1997). Building on Bull's work, I therefore define disgust as a methodological tool.

Why is it important to stay with disgust as an ethical and affective method of inquiry, or to call this 'affective intimacy'? First of all, as Myers says $(2015,1)$, it highlights the embodied reality of doing science "affectively". She argues that doing laboratory work requires technicians to "get entangled - kinesthetically and affectively - in their modelling efforts" $(2015,1$, italics in the original). I have discussed the kinesthesia of doing laboratory work in the previous section. In this section, I discuss disgust as an affective component of doing science. In other words, I tend toward what Myers defines as affect, namely "the energetics, intensities, and emotions that propagate through" laboratory work. This makes possible an ethic that does not rely on humanistic morality, but an ethics of relationality. Myers understands both the kinesthetic and affective realities of doing laboratory work as "feeling": not as emotions, that is, as the former highlights the feeling of the organism, while the latter refers to a feeling for the organism. Staying with such affective moments of intimacy in laboratory work is essential because it makes it possible for me to write about ethics and flies, which are 'the Other' not only of humans, but of a majority of the animal kingdom. In other words, flies are enacted as non-animal in the lab and are therefore killable. On the one hand, they are deemed killable because they do not feature anywhere in ethical guidelines, they are abject socio-culturally and they are not considered sentient beings. On the other hand they are deemed killable because they are one of the most valuable and prestigious laboratory models, perfectly black boxed and ready to use in any experiment across the world what Tora Holmberg and Malin Ideland (2009) call being an ordinary treasure. To stay with this position of being non-animal, which is often accompanied by fear and disgust, challenges existing ethics and ethical thinking in the humanities and social sciences, which are more attuned to the bigger and more familiar animals as the objects of (humanistic) ethics. In other words, as Bull (2014) writes, animals such as ticks are unlovable parasites with which humans rarely feel close. He argues that staying with the negative emotions that overwhelmed him in his encounters with ticks and attending to such dynamic emotions were crucial to his understanding of "human-animal interaction" because they told stories about how particular bodies are constructed as the undesirable, abject Other $(2014,79)$. His "aim is not to replace an ethics of love with one of disgust"; rather, he wishes to stay with the intensity of disgust to highlight what staying with disgust may create $(2014,80)$. As Bull writes, "parasitism and the disgust it conjures reemphasizes the politics of multi-species worlds" $(2014,80)$ and an ethics that is inspired by Harawayian response-ability. In other words, such affective intimacy can be a promising method of doing 
science ethically, as well as rethinking ethics in terms of complex relationalities.

I therefore suggest that disgust is an analytical tool with the potential to be made accountable to the empirical material, affective intimacies and embodied realities of knowledge production practices, therefore developing other ways of, as Knudsen and Stage write, "noticing and attending within our research endeavors". According to Knudsen and Stage (2015), affective method is a strategy for "asking research questions and formulating research agendas relating to affective processes, collecting or producing embodied data and making sense of these data in order to create academic knowledge". Such methodologies thus emphasize that knowledge production always already consists of intimate, bodily, fleeting and material processes.

\section{CONCLUSION}

In this article, in which I think with transgenic fruit flies in the context of laboratory work and the life sciences, I have discussed intimacy as transformative affective multispecies processes of becoming that are always already entangled with killing and death. I argued that, in the context of a fly lab, intimacy transgresses the boundaries of human-nonhuman, intimacy-distance, subject-object. I have suggested that adopting disgust as a tool makes a contribution to discussions of intimacy that detach intimacy from love, sexuality and human empathy, a form of sharing and caring that is mixed with killing. I also suggested that intimacy is a methodological tool, specifically an affective methodology. That is, I have discussed disgust and rotting smells in terms of stomach-wrenching affective moments of doing science and getting intimate with the flies, arguing that staying with such moments can provide different material, unorthodox ways of doing science, thereby producing other kinds of knowledge about bodies and the worlds they inhabit.

\section{Notes}

1. The male flies have darker genitalia (almost blackish), and the females have white genitalia. 2 . The plate constantly released nitrogen to keep the flies under sedation. Once they were moved away from the plate, the flies woke up quickly. 3 . Those with the exact genetic combinations I needed.

\section{REFERENCES}

- Ahmed, S. 2014. Cultural politics of emotion. Edinburgh: Edinburgh University Press.

- Alaimo, S. \& Hekman, S. eds. 2008. Material

feminisms. Bloomington, IN: Indiana University Press.

- Barad, K. 2007. Meeting the universe halfway: quantum physics and the entanglement of matter and meaning. Durham and London: Duke university Press.

- Birke, L., Bryld, M. and Lykke, N. 2004. Animal performances: an exploration of intersections between feminist science studies and studies of human/animal relationships. Feminist

Theory. 5(2): 167-183.

- Bull, J. 2014. Between ticks and people: responding to nearbys and contentments. Emotion, Space and Society. 12, 73-84.

- Gillespie, K. 2017. Intimacy, animal emotion and empathy: multispecies intimacy as slow research practice. In: Moss, P. and Donovan, C. eds.

Writing Intimacy Into Feminist Geography.

London and New York: Routledge, 160-171.

. Haraway, D. 1997. Modest_Witness@

Second_Millennium:

FemaleMan $\bigcirc \_$Meets_OncoMouse: feminism and technoscience. London and New York: Routledge.

- Haraway, D. 2008. When species meet.

Minneapolis: University of Minnesota Press.

- Holmberg, T. 2008. A feeling for the animal: on becoming an experimentalist. Society o Animals. 16(4), 316-335.

- Holmberg, T. 2011. Mortal love: care practices in animal experimentation. Feminist Theory. 12(2), 147-163.

. Holmberg, T. and Ideland, M. 2009. Transgenic silences: the rhetoric of comparisons and transgenic mice as 'ordinary treasures'. Biosocieties. $4(2), 165-181$.

- Jamison, L. 2011 . Intimacy as a concept: explaining social change in the context of globalisation or another form of ethnocentricism? Sociological Research Online. 16(4). 
- Jankowiak, W. R. and Paladino, T. 2008.

Desiring sex, longing for love: a tripartite conumdrum. In: Jankowiak, W. R. ed. Intimacies: Love and Sex Across Cultures. New York: Columbia University Press, 1-36.

- Knudsen, B. T. and Stage, C. 2015. Affective Methodologies: Developing Cultural Research Strategies for the Study of Affect. Basingtoke: Palgrave Macmillan.

- Morton, T. 2010. Queer ecology. PMLA. 125(2), 273-282.

- Nayar, P. K. 2014. Posthumanism. Cambridge and Malden: Polity Press.
. Pain, R. 2014. Gendered violence: rotating intimacy. Area. 46(4), 351-353.

- Sadowski, H. 2016. Digital Intimacies: Doing Digital Media Differently. Diss. Linköping University Electronic Press.

- Straube, W. Forthcoming. Posthuman Ecological Intimacy, Waste, and the Trans Body in Nånting måste gå sönder (2014). In: Vakoch, D.

ed. Transecology: Transgender Perspectives on Environment and Nature.

- Twine, R. 2010. Animals as Biotechnology: Ethics, Sustainability and Critical Animal Studies. New York: Routledge. 


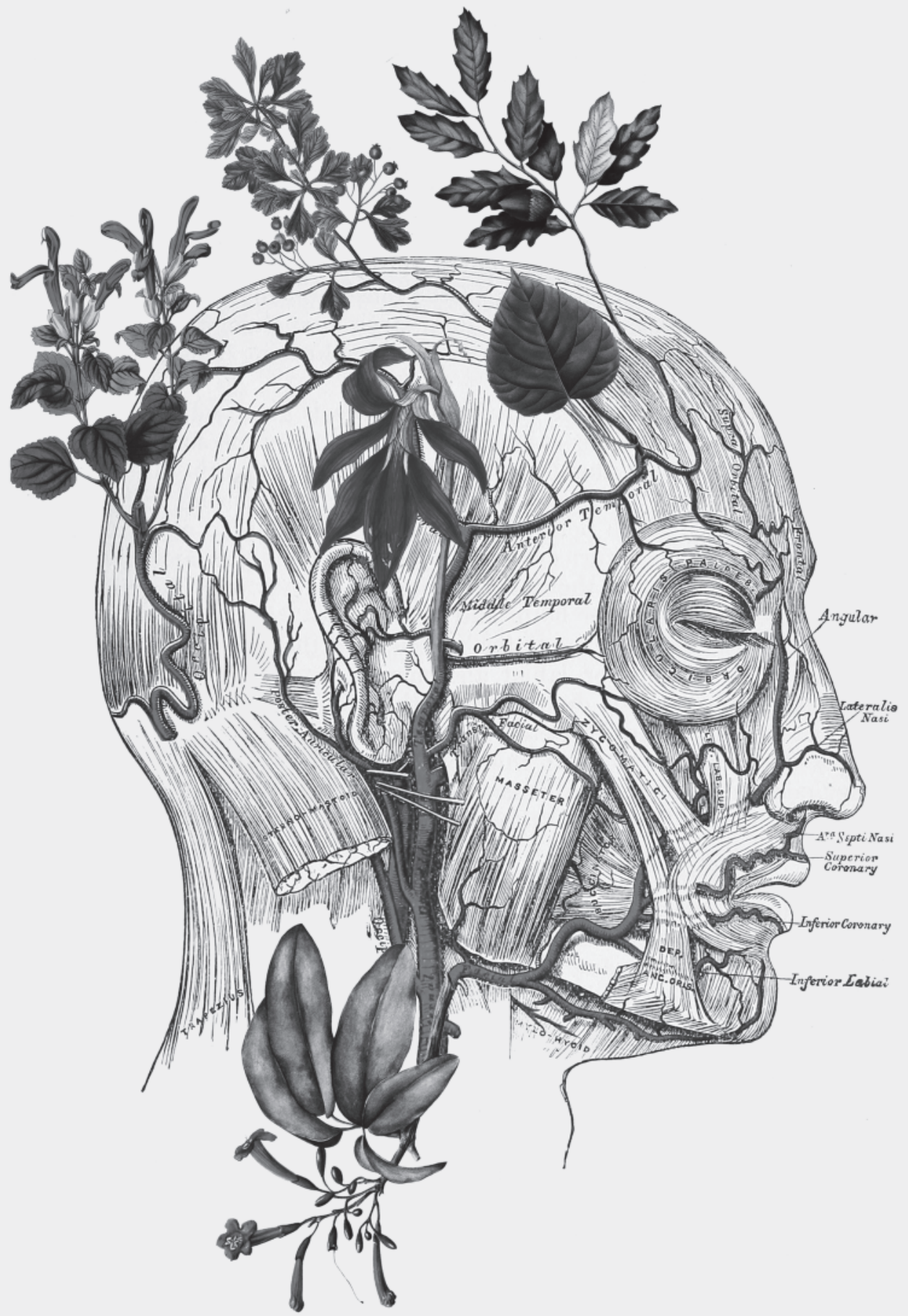

Jessi Jumanji “Fleurdepensee”. Collage Serie: Anatomme 